\title{
Emodin induces apoptosis of human breast cancer cells by modulating the expression of apoptosis-related genes
}

\author{
CONG ZU $^{1 *}$, MINGDI ZHANG $^{2 *}$, HUI XUE $^{3}$, XIAOPENG CAI $^{4}$, LEI ZHAO $^{5}$, ANNING HE $^{1}$, \\ GUANGYUAN QIN ${ }^{1}$, CHUNSHU YANG ${ }^{1}$ and XINYU ZHENG ${ }^{1,6}$
}

\begin{abstract}
${ }^{1}$ Lab 1, Cancer Institute, China Medical University, Shenyang, Liaoning 110001; ${ }^{2}$ Department of General Surgery, Xinhua Hospital, Shanghai Jiaotong University, School of Medicine, Shanghai 200092; ${ }^{3}$ Department of Gynecology, First Affiliated Hospital of China Medical University, Shenyang, Liaoning 110001; ${ }^{4}$ Department of Surgical Oncology, Zhongnan Hospital, Wuhan University, Wuhan, Hubei 430072; ${ }^{5}$ Center of Experiment Technology and Medical Research, China Medical University, Shenyang, Liaoning 110001; ${ }^{6}$ Department of Breast Surgery, First Affiliated Hospital, China Medical University, Shenyang, Liaoning 110001, P.R. China
\end{abstract}

Received November 15, 2014; Accepted July 28, 2015

DOI: $10.3892 / \mathrm{ol} .2015 .3646$

\begin{abstract}
The aim of this study was to investigate the effects of emodin on the proliferation of human breast cancer cells Bcap-37 and ZR-75-30. Cell viability following emodin treatment was assessed by 3-(4,5-dimethylthiazol-2-yl)2,5-diphenyltetrazolium bromide (MTT) assay. The effects of emodin on apoptosis were determined by flow cytometry using Annexin V-fluorescein isothiocyanate and propidium iodide staining. Quantitative polymerase chain reaction and western blot analysis were used to determine changes in the expression of apoptotic genes and protein, respectively. The effect of emodin on the invasiveness of breast cancer cells was evaluated by Matrigel invasion assay. Treatment of breast cancer cells Bcap-37 and ZR-75-30 with emodin was observed to inhibit the growth and induced apoptosis in a time- and dose-dependent manner. Emodin reduced the level of Bcl-2 and increased levels of cleaved caspase-3, PARP, p53 and Bax. These findings indicate that emodin induces growth inhibition and apoptosis in human breast cancer cells. Emodin may be a potential therapeutic agent for the treatment of breast cancer.
\end{abstract}

\section{Introduction}

Breast cancer is a common malignant tumor and accounts for the majority of cancer mortality in females (1). Breast cancer has an estimated incidence of 1,676,633 and had an estimated

Correspondence to: Professor Xinyu Zheng, Department of Breast Surgery, First Affiliated Hospital, China Medical University, 155 North Nanjing Street, Shenyang, Liaoning 110001, P.R. China E-mail: xyzheng@mail.cmu.edu.cn

${ }^{*}$ Contributed equally

Key words: emodin, breast carcinoma, apoptosis, growth inhibition mortality rate of 521,817 in 2012 worldwide (2). In China, there has been an increasing incidence of breast cancer in recent decades (3). In 2012, it was estimated that $\sim 48,000$ females would succumb to breast cancer. To date, chemotherapy has been the mainstay for the treatment of breast cancer. However, the side effects and drug resistance associated with chemotherapy have limited its effectiveness for the treatment of breast cancer $(4,5)$. A number of natural extractions have demonstrated a wide range of biological activity and low toxicity in animal models, and have been considered as an alternative method of breast cancer treatment $(6,7)$.

Emodin (1,3,8-trihydroxy-6-methylanthraquinone) is a biologically active anthraquinone identified in the roots and bark of a number of plants. Emodin is also observed naturally in a number of widely used Chinese medicinal herbs, including Rheum officinale (8) and Polygonam cuspidatummedicine (9). It has been widely studied for its antibacterial, diuretic, immunosuppressive, anti-inflammatory and vasorelaxant effects. It has been reported that emodin induces apoptosis of several types of human cancer cells (10-13) by modulating various signaling pathways. However, the biological mechanisms by which emodin induces cytotoxicity remain largely unknown. Furthermore, the biological effects of emodin on breast cancer cells remain to be determined.

In this study, the effects of emodin on the proliferation and apoptosis of breast cancer cells were assessed. In addition, the mechanism by which emodin mediates these biological effects was elucidated. We demonstrated that emodin inhibited the proliferation and induced apoptosis of Bcap-37 and ZR-75-30 breast cancer cells. These observations suggest that emodin may be a potential agent in the treatment of breast cancer.

\section{Materials and methods}

Drugs and antibodies. Emodin was purchased from Sigma-Aldrich (St. Louis, MO, USA). A stock solution of emodin $(10 \mathrm{mg} / \mathrm{ml})$ was prepared in dimethyl sulfoxide (DMSO) and further diluted in culture medium. DMSO 
$(0.05 \%)$ was used as vehicle control in all experiments. The antibodies used for western blot analysis were as follows: anti-cleaved caspase-3 (\#9661), anti-Bcl-2 (\#2876), anti-Bax (\#2772), anti-PARP (\#9532), anti-p53 (\#2527) and anti- $\beta$-actin (\#4970). All antibodies were purchased from Cell Signaling Technology, Inc. (Danvers, MA, USA).

Cell culture. Human breast cancer cells Bcap-37 and ZR-75-30 were obtained from the Cell Resource Center of Shanghai Life Science Research Institute, Chinese Academy of Sciences and cultured in RPMI-1640 medium (Invitrogen Corporation, Grand Island, NY, USA) supplemented with $10 \%$ fetal bovine serum (FBS; Thermo Scientific Hyclone, Logan, UT, USA), $100 \mu \mathrm{g} / \mathrm{ml}$ streptomycin and $100 \mathrm{U} / \mathrm{ml}$ penicillin at $37^{\circ} \mathrm{C}$ in a humidified incubator in an atmosphere of $5 \% \mathrm{CO}_{2}$.

Cell viability assay. Cells were trypsinized and seeded into 96-well plates (Corning, Tewksbury, MA, USA) at a density of $1 \times 10^{4}$ cells per well and incubated overnight. The cells were replenished with fresh medium containing various concentrations $(0,10,20,40$ and $80 \mu \mathrm{M})$ of emodin for 24,48 and $72 \mathrm{~h}$. At each time point, $10 \mathrm{ml}$ of $5 \mathrm{mg} / \mathrm{ml} \mathrm{3-(4,5-dimethylthiazol-}$ 2-yl)-2,5-diphenyltetrazolium bromide (MTT; Sigma-Aldrich) solution was added into each well and incubated for an additional $4 \mathrm{~h}$ at $37^{\circ} \mathrm{C}$. The culture medium was then removed, and $100 \mu \mathrm{l}$ DMSO was added into each well. The absorbance was recorded at $490 \mathrm{~nm}$ on a microplate reader (BioTek, Winooski, VT, USA). The results represent the average values of three experiments. Each experiment was performed at least three times.

Apoptosis analysis. Apoptosis was evaluated by Annexin V-fluorescein isothiocyanate (Annexin V-FITC; KeyGEN Biotech, Nanjing, China). Cells were treated with emodin $(0,10$ and $40 \mu \mathrm{M})$ for $24 \mathrm{~h}$. Then, $5 \times 10^{5}$ cells were collected, resuspended in $500 \mathrm{ml}$ binding buffer containing an additional $5 \mu \mathrm{l}$ Annexin V-FITC and $5 \mu \mathrm{l}$ propidium iodide, and incubated for $15 \mathrm{mins}$ at room temperature without direct sunlight. Samples were analyzed by flow cytometry (BD Pharmingen, San Diego, CA, USA). Experiments were performed at least three times.

Quantitative polymerase chain reaction ( $q P C R)$. Breast cancer cells were treated with emodin $(0,10$ and $40 \mu \mathrm{M})$ for $24 \mathrm{~h}$. Total RNA was extracted by the RNAiso Plus kit (Takara, Dalian, China). First-strand complementary DNA (cDNA) was synthesized using the PrimeScript RT reagent kit (Takara) according to the instructions. Amplification of the cDNA for PCR was performed in a reaction volume of $20 \mu \mathrm{l}$ which included $2 \mu \mathrm{l}$ cDNA. The primer sequences used were as follows: p53 (forward, ATCCTCACCATCATCACACTGG; reverse, ACAAACACGCACCTCAAAGC); Bcl-2 (forward, CAAATGCTGGACTGAAAAATTGTA; reverse, TATTTT CTAAGGACGGCATGATCT); Bax (forward, GACACC TGAGCTGACCTTGG; reverse: AGGAAGTCCAGTGTCC AGC); $\beta$-actin (forward, CTGGGACGACATGGAGAAAA, reverse: AAGGAAGGCTGGAAGAGTGC). The PCR cycling conditions were as follows: $95^{\circ} \mathrm{C}$ for $30 \mathrm{sec}$ followed by 40 cycles at $95^{\circ} \mathrm{C}$ for $5 \mathrm{sec}$, and annealing at $60^{\circ} \mathrm{C}$ for $30 \mathrm{sec}$. Each experiment was repeated three times. $\beta$-actin was used as an internal reference gene to normalize gene expression. Relative gene expression was analyzed by the comparative threshold cycle $(\mathrm{Ct})$ method. The value was used to plot the expression of apoptotic genes by $2^{-\Delta \Delta C t}$.

Matrigel invasion assay. Transwell chambers (Corning) were used to assess the invasiveness of breast cancer cells. Two chambers were separated by Matrigel-coated polycarbonate membrane $(6.5-\mathrm{mm}$ diameter inserts with an $8-\mu \mathrm{m}$ pore size). Cells were treated with FBS-free medium for $24 \mathrm{~h}$, and $5 \times 10^{5}$ cells $/ \mathrm{ml}$ with various concentrations of emodin $(0,10$ and $40 \mu \mathrm{M})$ in a total volume of $200 \mu 1$ were placed in the upper chamber. A total of $500 \mu 1$ RPMI-1640 medium and $10 \%$ FBS were added to the lower chamber. After $24 \mathrm{~h}$, the cells remaining on the upper surface of the filter were removed with a cotton swab. The membrane was fixed with methanol and then stained with crystal violet. Cell migration was measured by a cell staining count in five separate areas using a light microscope (Olympus BX41; Olympus Inc., Center Valley, PA, USA). Each experiment was performed at least three times.

Western blot analysis. Western blot analysis was used to detect the levels of apoptotic protein. Breast cancer cells were treated with various concentrations of emodin $(0,10$ and $40 \mu \mathrm{M}$ ) for $24 \mathrm{~h}$. Cells were harvested and lysed in lysis buffer (Beyotime Biotech, Shanghai, China). The total protein concentration of the cell was determined by the bicinchoninic acid assay (KeyGEN Biotech). Forty micrograms of protein were separated by electrophoresis on $10 \%$ sodium dodecyl sulphate-polyacrylamide gel. The gel was then transferred to polyvinylidene fluoride membranes, and then blocked for $2 \mathrm{~h}$ with Tris-buffered saline and Tween-20 containing 5\% non-fat milk. Next, the membranes were incubated with the primary antibodies at $4^{\circ} \mathrm{C}$ overnight. This was followed by incubation at room temperature with the appropriate horseradish peroxidase-conjugated secondary antibodies for $2 \mathrm{~h}$. The results were detected using an electrochemiluminesence kit (Pierce, Rockford, IL, USA).

Statistical analysis. All assays were performed independently in triplicate. All values were expressed as mean \pm standard deviation and analyzed by Student's t-test using SPSS 19.0 software (IBM SPSS, Armonk, MY, USA). P $<0.05$ was considered to indicate a statistically significant difference.

\section{Results}

Effects of emodin on the viability of breast cancer cells. The effects of emodin on the growth of Bcap-37 and ZR-75-30 cells were measured by MTT assay. As shown in Fig. 1, emodin significantly inhibited the growth of Bcap-37 and ZR-75-30 cells in a time- and dose-dependent manner. The highest rates of decreased growth were observed using at least $10 \mu \mathrm{mol} / 1$ emodin for $72 \mathrm{~h}$ (Fig. 1Aa and $\mathrm{Ba} ; \mathrm{P}<0.05$ ). This result suggests that emodin inhibited the proliferation of Bcap-37 and ZR-75-30 cells.

Effects of emodin on apoptosis. To determine whether the growth inhibition by emodin is associated with apoptosis, 

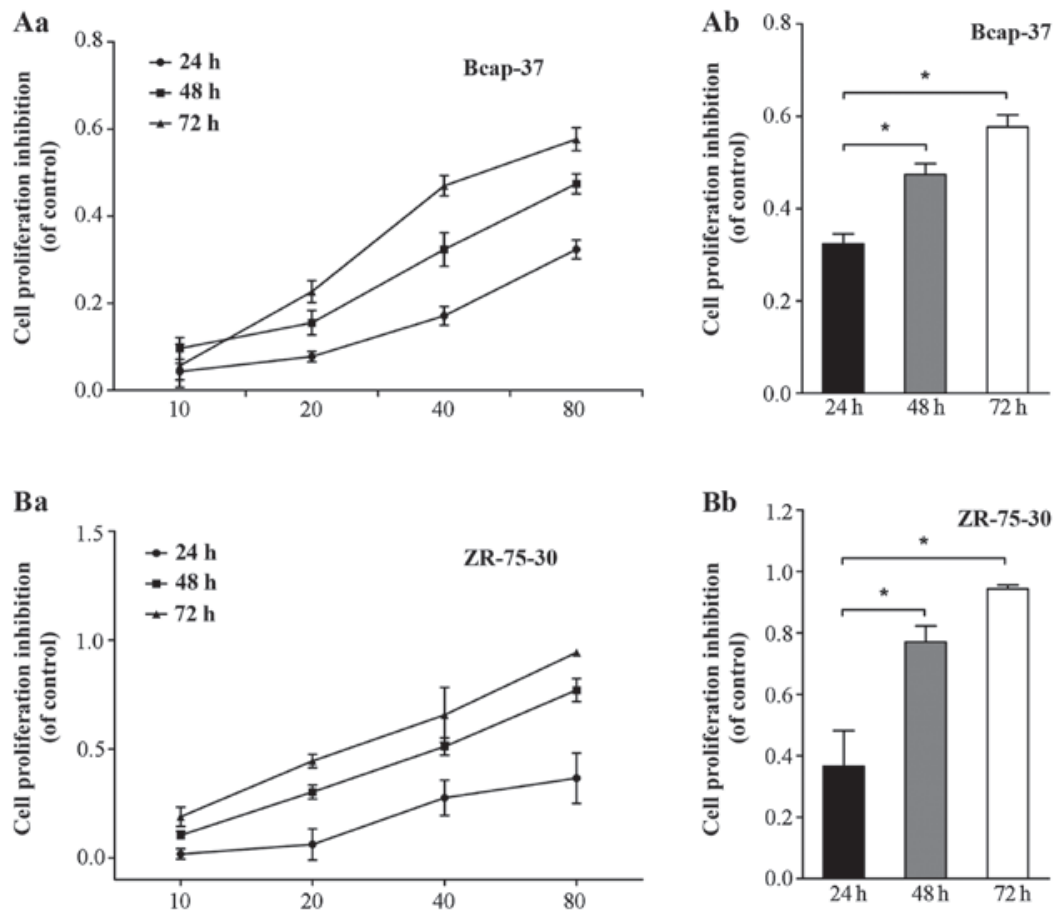

Figure 1. Effects of emodin on cell viability of Bcap-37 and ZR-75-30 cells. (Aa and Ab) Inhibitory effect of emodin on proliferation of Bcap-37 cells (Ba and $\mathrm{Bb}$ ) Inhibitory effect of emodin on proliferation of ZR-75-30 cells. ${ }^{*} \mathrm{P}<0.05$ vs. control.

A
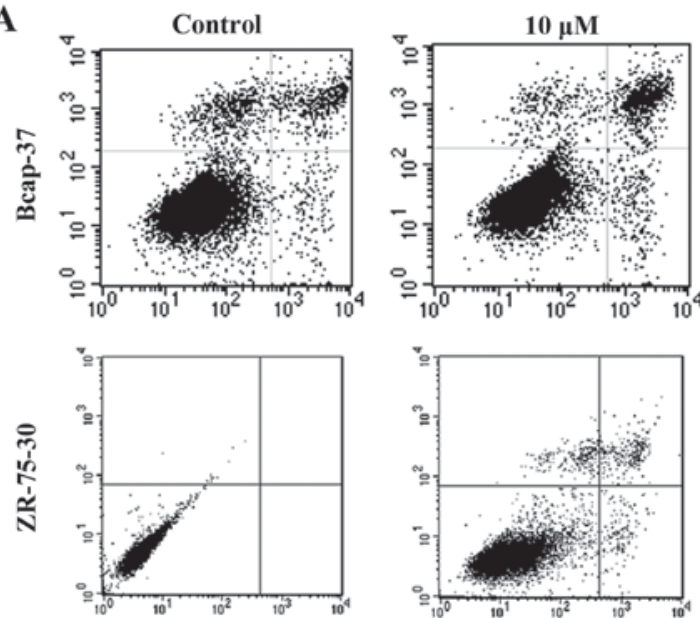
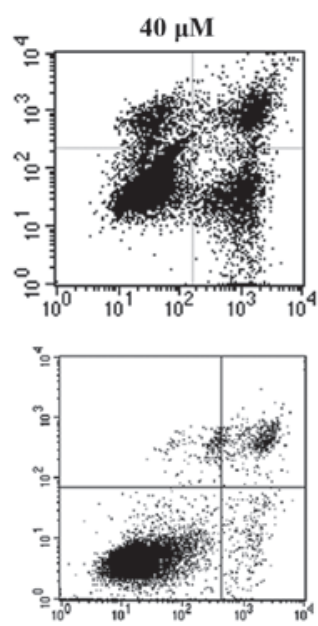

B
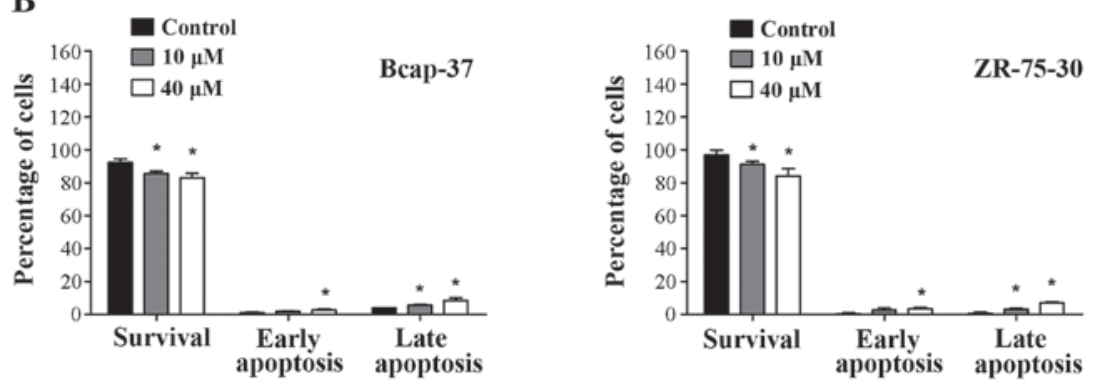

Figure 2. Effects of emodin on apoptosis of Bcap-37 and ZR-75-30 cells. (A) Emodin-induced apoptosis analyzed by flow cytometry at doses of 0, 10 and $40 \mu \mathrm{M}$ for $24 \mathrm{~h}$. (B) Emodin-induced apoptosis rate shown by bar graph. ${ }^{*} \mathrm{P}<0.05$ vs. control.

flow cytometry analysis was performed. Significant apoptosis induced by emodin was observed in Bcap-37 and ZR-75-30 cells in a concentration-dependent manner (Fig. 2; $\mathrm{P}<0.05$ ).
Apoptotic rates were highest when using emodin at $40 \mu \mathrm{M}$. These results indicate that emodin induced apoptosis of breast cancer cells. 
A

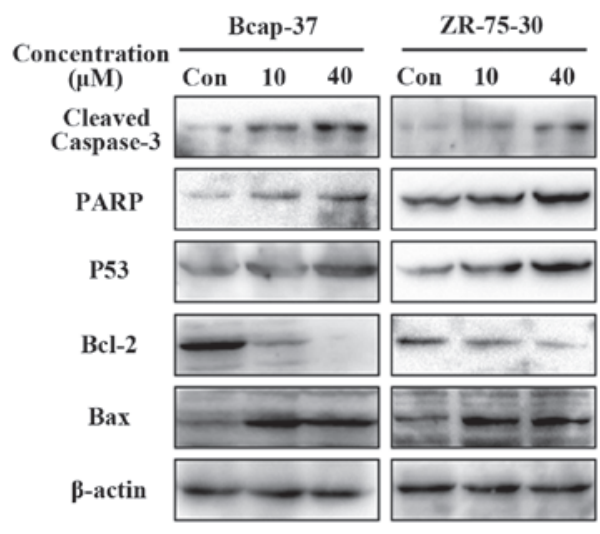

B
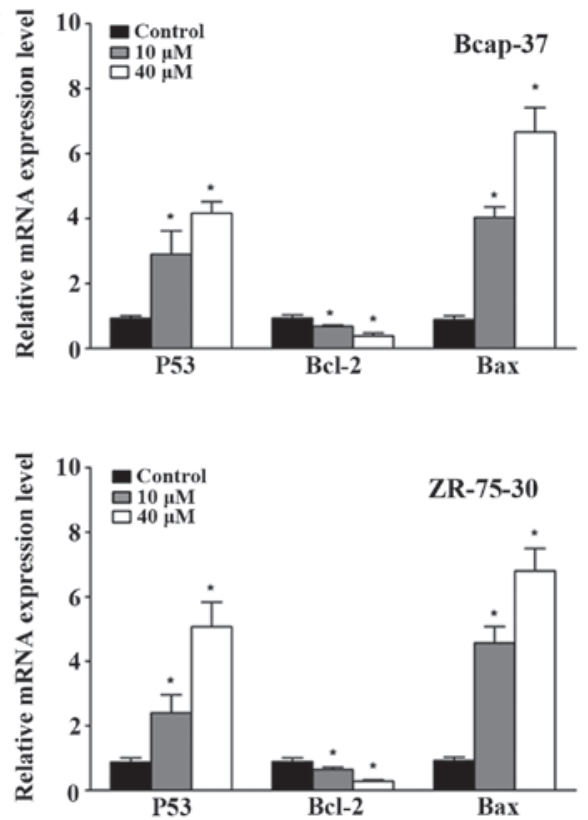

Figure 3. Effects of emodin on apoptosis-related protein and mRNA in Bcap-37 and ZR-75-30 cells. (A) Alteration of cleaved caspase-3, PARP, p53, Bcl-2 and Bax protein following treatment with emodin $(0,10$ and $40 \mu \mathrm{M})$ for $24 \mathrm{~h}$. (B) Relative mRNA expression level of p53, Bcl-2 and Bax. "P<0.05 vs. control.

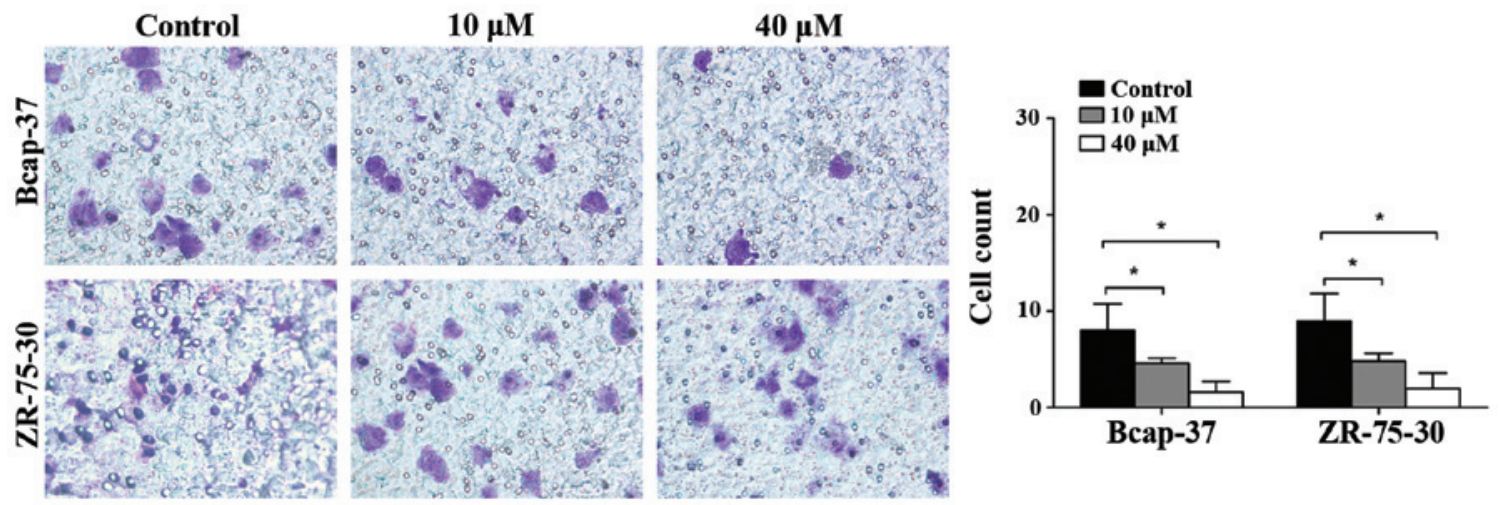

Figure 4. Effects of emodin on invasion of Bcap-37 and ZR-75-30 cells. "P<0.05 vs. control.

Effects of emodin on caspase activation and Bcl-2 family members. To investigate the effects of emodin on the molecular mechanisms associated with apoptosis in breast cancer cells, the expression of apoptosis-related proteins was analyzed by western blot analysis. Emodin treatment downregulated Bcl-2 expression while increasing caspase-3 activation, PARP, p53 and Bax levels in breast cancer cells in a concentration-dependent manner (Fig. 3A). Similar observations were made with respect to the mRNA level by qPCR, with significant increases in Bax levels, and decreases in $\mathrm{p} 53$ and Bcl-2 (Fig. 3B; $\mathrm{P}<0.05$ ). These observations provide further support that emodin induces apoptosis of breast cancer cells.

Effects of emodin on cell invasion. The effects of emodin on the invasiveness of breast cancer cells were assessed by the Matrigel invasion assay. As shown in Fig. 4, emodin decreased the number of Bcap-37 and ZR-75-30 cells invading through the Matrigel at $24 \mathrm{~h}$ in a concentration-dependent manner. Transwell assay demonstrated that the invasiveness of Bcap-37 and ZR-75-30 cells was suppressed by emodin.

\section{Discussion}

Emodin is a natural anthraquinone and an inhibitor of tyrosine kinase (14). Emodin is derived from rhubarb and numerous other plants, and has demonstrated antibacterial, antiviral, anti-inflammatory and anticancer effects (15). However, previous studies have revealed that emodin inhibits cell growth in several types of cancer cells by regulating genes related to apoptosis, oncogenesis, proliferation and cancer cell invasion and metastasis $(10,16,17)$. Notably, emodin inhibited epithelial-mesenchymal transition, suggesting that emodin may have anticancer effects (18). Additionally, a study demonstrated that emodin enhanced anticancer effects when used in combination with gemcitabine (19). However, little is known about the effects of emodin in breast cancer cells. In this study, we assessed the effects of emodin on the growth, apoptosis and invasiveness of Bcap-37 and ZR-75-30 breast cancer cells.

In this study, emodin induced apoptosis of Bcap-37 and ZR-75-30 cells in a dose- and time-dependent manner. 
Furthermore, flow cytometric analysis demonstrated a significant increase in the number of Bcap-37 and ZR-75-30 cells in the early and late apoptosis phase. Emodin also inhibited the invasiveness of these cells, as demonstrated by the Matrigel invasion assay. These findings suggest that emodin functions by inhibiting the growth and invasion of tumor cells.

Cell apoptosis is an autonomous cell death process that regulates the development and homeostasis of multicellular organisms (20). A key strategy for drug development is to induce apoptosis of cancer cells while minimizing the damage to normal and healthy cells (21). The induction of apoptosis in cancer cells has been described as a key mechanism in anticancer therapy $(22,23)$.

Apoptosis is regulated by the Fas and mitochondrial signaling pathways (24). The tumor suppressor gene p53 plays a significant role in genomic stability, anticancer activity, protection against malignant transformation, and induction of apoptosis $(25,26)$. p53 is a transcriptional factor that upregulates the expression of downstream genes involved in cell cycle arrest, senescence, autophagy and apoptosis. The p53 protein is also involved in apoptosis, partly by inducing Bax expression (27). Bcl-2 is an inhibitor of the mitochondrial apoptotic pathway, which prevents the release of cytochrome $c$ and caspase activation by blocking the effects of pro-apoptotic proteins (28). Among the Bcl-2 gene family, the apoptosis-promoting protein Bax and the anti-apoptotic protein $\mathrm{Bcl}-2$ play a crucial role in regulating cell apoptosis $(29,30)$, which depends on the occurrence and severity of apoptosis (30). In our study, a dose-dependent decrease in Bcl-2 expression and an increase in Bax expression was observed following emodin treatment in Bcap-37 and ZR-75-30 cells. These observations demonstrate that emodin-induced apoptosis of Bcap-37 and ZR-75-30 cells was triggered by the downregulation of $\mathrm{Bcl}-2$ and the upregulation of Bax. Previous studies have demonstrated that the mitochondrial membrane potential stimulates the opening of the mitochondrial membrane, resulting in the release of cytochrome $c$ into the cytoplasm, caspase activation and degradation of key intracellular proteins, which leads to apoptosis $(31,32)$.

Caspase- 3 exists in the cytoplasm as an inactive zymogen. When activated by the external apoptotic signals, caspase-3 induces the inactivation of a number of key proteases in the cytoplasm, cell nucleus and cytoskeleton, which subsequently induces apoptosis (33). The cleavage of apoptosis-related proteins, caspase-9, caspase- 3 and PARP is accompanied by cytochrome $c$ release. In this study, the cleavage of caspase-3 expression and the alteration of PARP were in accordance with the tendency of cell apoptosis (34).

In summary, we have demonstrated in the present study that emodin significantly inhibited the growth and invasiveness, and induced the apoptosis of human breast cancer cells in a dose- and time-dependent manner. These processes were also associated with caspase and PARP activation, increased levels of p53 and Bax, and decreased levels of Bcl-2. Further studies are needed in the future in order to elucidate the biological and molecular mechanisms of emodin for the treatment of breast cancer. Overall, this study suggests that emodin is a potential therapeutic agent for the treatment of breast cancer.

\section{Acknowledgements}

This study was supported by grants from the National Natural Science Foundation of China (no. 81172199 and 81272920).

\section{References}

1. Sanguinetti A, Polistena A, Lucchini R, Monacelli M, Avenia S, Conti C, Barillaro I, Rondelli F, Bugiantella W and Avenia N: Breast cancer in older women: What factors affect the treatment? Int J Surg 12 (Suppl 2): S177-S180, 2014.

2. Ferlay J, SI, Ervik M, Dikshit R, Eser S, Mathers C, Rebelo M, Parkin DM, Forman D and Bray F: GLOBOCAN 2012 v1.0, Cancer Incidence and Mortality Worldwide: IARC CancerBase No. 11, Lyon, France. International Agency for Research on Cancer; 2013. http://globocan.iarc.fr. Accessed December 12, 2013.

3. Zeng H, Zheng R, Zhang S and Zou X, Chen W: Female breast cancer statistics of 2010 in China: Estimates based on data from 145 population-based cancer registries. J Thorac Dis 6: 466-470, 2014.

4. Lin G, Zhu W, Yang L, Wu J, Lin B, Xu Y, Cheng Z, Xia C, Gong Q, Song B and Ai H: Delivery of siRNA by MRI-visible nanovehicles to overcome drug resistance in MCF-7/ADR human breast cancer cells. Biomaterials 35: 9495-9507, 2014.

5. Amirzada MI, Ma X, Gong X, Chen Y, Bashir S and Jin J: Recombinant human interleukin 24 reverses Adriamycin resistance in a human breast cancer cell line. Pharmacol Rep 66: 915-919, 2014.

6. Bright-Gbebry M, Makambi KH, Rohan JP, Llanos AA, Rosenberg L, Palmer JR and Adams-Campbell LL: Use of multivitamins, folic acid and herbal supplements among breast cancer survivors: the black women's health study. BMC Complement Altern Med 11: 30, 2011.

7. Spazzapan S, Crivellari D, Bedard P, Lombardi D, Miolo G, Scalone S and Veronesi A: Therapeutic management of breast cancer in the elderly. Expert Opin Pharmacother 12: 945-960, 2011.

8. Li WY, Chan SW, Guo DJ, Chung MK, Leung TY and Yu PH: Water extract of Rheum officinale Baill. induces apoptosis in human lung adenocarcinoma A549 and human breast cancer MCF-7 cell lines. J Ethnopharmacol 124: 251-256, 2009.

9. Wang C, Wu X, Chen M, Duan W, Sun L, Yan M and Zhang L: Emodin induces apoptosis through caspase 3-dependent pathway in HK-2 cells. Toxicology 231: 120-128, 2007.

10. Li WY, Ng YF, Zhang H, Guo ZD, Guo DJ, Kwan YW, Leung GP, Lee SM, Yu PH and Chan SW: Emodin elicits cytotoxicity in human lung adenocarcinoma A549 cells through inducing apoptosis. Inflammopharmacology 22: 127-134, 2014.

11. Li WY, Chan RY, Yu PH and Chan SW: Emodin induces cytotoxic effect in human breast carcinoma MCF-7 cell through modulating the expression of apoptosis-related genes. Pharm Biol 51: 1175-1181, 2013.

12. Sui JQ, Xie KP, Zou W and Xie MJ: Emodin inhibits breast cancer cell proliferation through the ER $\alpha$-MAPK/Akt-cyclin D1/Bcl-2 signaling pathway. Asian Pac J Cancer Prev 15: 6247-6251, 2014.

13. Pooja T and Karunagaran D: Emodin suppresses Wnt signaling in human colorectal cancer cells SW480 and SW620. Eur J Pharmacol 742: 55-64, 2014

14. Wei WT, Lin SZ, Liu DL and Wang ZH: The distinct mechanisms of the antitumor activity of emodin in different types of cancer (Review). Oncol Rep 30: 2555-2562, 2013.

15. Xu JD, Liu S, Wang W, Li LS, Li XF, Li Y, Guo H, Ji T, Feng XY, Hou XL, et al: Emodin induces chloride secretion in rat distal colon through activation of mast cells and enteric neurons. Br J Pharmacol 165: 197-207, 2012.

16. Xue H, Chen Y, Cai X, Zhao L, He A, Guo K and Zheng X: The combined effect of survivin-targeted shRNA and emodin on the proliferation and invasion of ovarian cancer cells. Anticancer Drugs 24: 937-944, 2013.

17. Yaoxian W, Hui Y, Yunyan Z, Yanqin L, Xin G and Xiaoke W: Emodin induces apoptosis of human cervical cancer hela cells via intrinsic mitochondrial and extrinsic death receptor pathway. Cancer Cell Int 13: 71, 2013.

18. Way TD, Huang JT, Chou CH, Huang CH, Yang MH and Ho CT: Emodin represses TWIST1-induced epithelial-mesenchymal transitions in head and neck squamous cell carcinoma cells by inhibiting the $\beta$-catenin and Akt pathways. Eur J Cancer 50: 366-378, 2014. 
19. Lin SZ, Wei WT, Chen H, Chen KJ, Tong HF, Wang ZH, Ni ZL, Liu HB, Guo HC and Liu DL: Antitumor activity of emodin against pancreatic cancer depends on its dual role: Promotion of apoptosis and suppression of angiogenesis. PLoS One 7: e42146, 2012.

20. Muppidi J, Porter M and Siegel RM: Measurement of apoptosis and other forms of cell death. Curr Protoc Immunol: doi: 10.1002/0471142735.im0317s59.

21. Evan GI and Vousden KH: Proliferation, cell cycle and apoptosis in cancer. Nature 411: 342-348, 2001.

22. Kelly PN and Strasser A: The role of Bcl-2 and its pro-survival relatives in tumourigenesis and cancer therapy. Cell Death Differ 18: 1414-1424, 2011.

23. Strasser A, Cory S and Adams JM: Deciphering the rules of programmed cell death to improve therapy of cancer and other diseases. EMBO J 30: 3667-3683, 2011.

24. Heath RM, Jayne DG, O'Leary R, Morrison EE and Guillou PJ: Tumour-induced apoptosis in human mesothelial cells: A mechanism of peritoneal invasion by Fas Ligand/Fas interaction. Br J Cancer 90: 1437-1442, 2004.

25. Geng QQ, Dong DF, Chen NZ, Wu YY, Li EX, Wang J and Wang SM: Induction of 553 expression and apoptosis by a recombinant dual-target MDM2/MDMX inhibitory protein in wild-type p53 breast cancer cells. Int J Oncol 43: 1935-1942, 2013.

26. Harris SL and Levine AJ: The p53 pathway: positive and negative feedback loops. Oncogene 24: 2899-2908, 2005.

27. Leard LE and Broaddus VC: Mesothelial cell proliferation and apoptosis. Respirology 9: 292-299, 2004.
28. Fang CC, Yen CJ, Tsai TJ, Chen RH, Lee PH and Tomino Y: Antibiotics induce apoptosis of human peritoneal mesothelial cells. Nephrology (Carlton) 8: 142-149, 2003.

29. Korsmeyer SJ, Shutter JR, Veis DJ, Merry DE and Oltvai ZN Bcl-2/Bax: a rheostat that regulates an anti-oxidant pathway and cell death. Semin Cancer Biol 4: 327-332, 1993.

30. Lindsay J, Esposti MD and Gilmore AP: Bcl-2 proteins and mitochondria-specificity in membrane targeting for death. Biochim Biophys Acta 1813: 532-539, 2011.

31. Ma L and Li W: Emodin inhibits LOVO colorectal cancer cell proliferation via the regulation of the $\mathrm{Bcl}-2 / \mathrm{Bax}$ ratio and cytochrome c. Exp Ther Med 8: 1225-1228, 2014.

32. Wang $X$ : The expanding role of mitochondria in apoptosis. Genes Dev 15: 2922-2933, 2001.

33. Liu TY, Tan ZJ, Jiang L, Gu JF, Wu XS, Cao Y, Li ML, Wu KJ and Liu YB: Curcumin induces apoptosis in gallbladder carcinoma cell line GBC-SD cells. Cancer Cell Int 13: 64, 2013.

34. Liu J, Wu N, Ma LN, Zhong JT, Liu G, Zheng LH and Lin XK: p38 MAPK signaling mediates mitochondrial apoptosis in cancer cells induced by oleanolic acid. Asian Pac J Cancer Prev 15: 4519-4525, 2014. 